\title{
Diffuse unilateral subacute neuroretinitis in a young boy: a case report
}

This article was published in the following Dove Press journal:

Clinical Ophthalmology

23 March 2012

Number of times this article has been viewed

\section{Ng Guan-Fook \\ Abd Aziz Hayati \\ Mohd Noor Raja-Azmi \\ Ahmad Tajudin Liza- \\ Sharmini \\ Wan Hitam Wan-Hazabbah \\ Embong Zunaina}

Department of Ophthalmology, School of Medical Science, Universiti Sains Malaysia, Kubang Kerian, Kelantan, Malaysia
Correspondence: Embong Zunaina Department of Ophthalmology, School of Medical Science, Universiti Sains Malaysia, 16150 Kubang Kerian, Kelantan, Malaysia

Tel +609767 6362

Fax +609765 3370

Email zunaina@kb.usm.my
Abstract: We report a case of diffuse unilateral subacute neuroretinitis in a young boy with no clinical visualization of nematode. The diagnosis was made based on clinical findings and detection of Toxocara immunoglobulin G by Western blot test. An 11-year-old Malay boy presented with progressive blurring of vision in the left eye for a duration of 1 year. It was associated with intermittent floaters. Visual acuity in the left eye was 6/45 and improved to 6/24 with pinhole. There was positive relative afferent pupillary defect, impaired color vision, and presence of red desaturation in the left eye. There were occasional cells in the anterior chamber with no conjunctiva injection. Posterior segment examination revealed mild-to-moderate vitritis and generalized pigmentary changes of the retina with attenuated vessels. The optic disk was slightly hyperemic with mild edema. There was presence of multiple, focal, graywhite subretinal lesions at the inferior part of the retina. Full blood picture results showed eosinophilia with detection of Toxocara immunoglobulin $\mathrm{G}$ by Western blot test. Investigations for other infective causes and connective tissue diseases were negative. The diagnosis of diffuse unilateral subacute neuroretinitis secondary to Toxocara was made based on clinical findings and laboratory results. He was treated with oral albendazole $400 \mathrm{mg}$ daily for 5 days and oral prednisolone $1 \mathrm{mg} / \mathrm{kg}$ with tapering doses over 6 weeks. At 1 month follow-up, the inflammation had reduced, and multiple, focal, gray-white subretinal lesions were resolved; however there was no improvement of vision.

Keywords: diffuse unilateral subacute neuroretinitis, Toxocara IgG, albendazole

\section{Introduction}

Diffuse unilateral subacute neuroretinitis (DUSN) is a progressive ocular infectious disease caused by a variety of nematode species that involve the outer retina and retinal pigment epithelium. In 1978, Gass et al hypothesized that Toxocara was the cause of DUSN. ${ }^{1}$ However in 1983, Gass and Braunstein discovered that DUSN is caused by a nematode and that the nematode is probably not Toxocara canis. ${ }^{2}$ Other species of nematodes have been identified including Ancylostoma caninum, Bayliscariasis procyonis, Strongyloides sp, Alaria mesocercaria, and filarial worms. ${ }^{3,4}$ Most cases demonstrated the presence of larva or migrating nematode in the retina or subretinal space to establish the diagnosis. However in the absence of clinical visualization of nematode, diagnosis is challenging.

We report a case of DUSN in a young boy with no clinical visualization of nematode. The diagnosis was made based on clinical findings and detection of Toxocara immunoglobulin $\mathrm{G}(\mathrm{IgG})$ by Western blot test. 


\section{Case presentation}

An 11-year-old Malay boy presented with progressively painless blurring of vision in the left eye for a duration of 1 year. It was associated with intermittent floaters. He had a history of close contact with a cat.

On examination, visual acuity in the left eye was $6 / 45$ and improved to $6 / 24$ with pinhole. There was positive relative afferent pupillary defect, impaired color vision, and presence of red desaturation in the left eye. There were occasional cells in the anterior chamber with no conjunctiva injection. Posterior segment examination revealed mild-to-moderate vitritis, and generalized pigmentary changes of the retina with attenuated vessels (Figure 1). The optic disk was slightly hyperemic with mild edema. There was presence of multiple, focal, gray-white subretinal lesions at the inferior part of the retina. Visual acuity in the right eye was $6 / 6$ with normal anterior and posterior segment examination. Systemic examination was unremarkable.

Full blood picture results showed eosinophilia with detection of Toxocara IgG by Western blot test. Investigations for other infective causes such as syphilis, toxoplasmosis, retrovirus, herpes, and connective tissue diseases were negative. Electroretinogram (ERG) of the left eye showed both scotopic and photopic ERG reduction of amplitude in a-wave and b-wave. There were normal ERG findings in the right eye.

Based on clinical findings and investigations, a diagnosis of DUSN secondary to Toxocara was made. The patient was treated with oral albendazole $400 \mathrm{mg}$ daily for 5 days and oral prednisolone $1 \mathrm{mg} / \mathrm{kg}$ with tapering doses over 6 weeks. At 1 month follow-up, the inflammation had reduced, and multiple, focal, gray-white subretinal lesions were resolved; however there was no improvement of vision.

\section{Discussion}

DUSN is a progressive ocular infectious disease caused by parasites that involve the outer retina and retinal pigment epithelium. The pathogenesis is incompletely understood. It is believed to be caused by toxic inflammation from larva products and host immune immunological response. ${ }^{5}$

Patients with DUSN are often unaware of their eye condition during early stages of the disease. Most patients only realize when they suffer severe deterioration of their vision. Patients may present with mild-to-moderate visual loss and floaters with visual field defects during the early stages. In late stage DUSN, they may suffer from severe visual loss and paracentral or central scotomas. Retinitis is the most characteristic clinical manifestation but it may masquerade as a white dot syndrome. ${ }^{6}$ Other clinical findings include anterior uveitis, vitritis, narrowing of the retinal vessels, optic disk swelling, and atrophy.

Several cases reported identification of parasites in the subretinal space which is the pathognomonic finding in DUSN. ${ }^{7}$ A detailed search to locate the worms by using contact lens or indirect ophthalmoscopy is important to establish the diagnosis. Early diagnosis may not only prevent further loss of vision but may also improve vision in some patients. ${ }^{7}$ Stool examinations for ova and parasites, peripheral blood smears, serologic testing, and Western blot test support and assist the diagnosis of ocular toxocariasis. ${ }^{2,8}$

In patients with late-stage DUSN there is reduced nerve fiber layer thickness. ${ }^{9}$ ERG can be used to assess the functional status of the retina. Studies have shown that a- and b-wave amplitude was reduced in the affected eye in all stages of the disease $e^{4,10-12}$ and that $b$-wave is normally affected more than a-wave (Table 1 ). The unaffected eye has normal ERG findings. Thus, ERG can be used to monitor progression of the disease and effectiveness of treatment. Similar findings were noted in our patient; amplitude of a-wave and b-wave were reduced in the affected eye.

The first choice of treatment in DUSN is laser photocoagulation. It is highly effective when the worm is

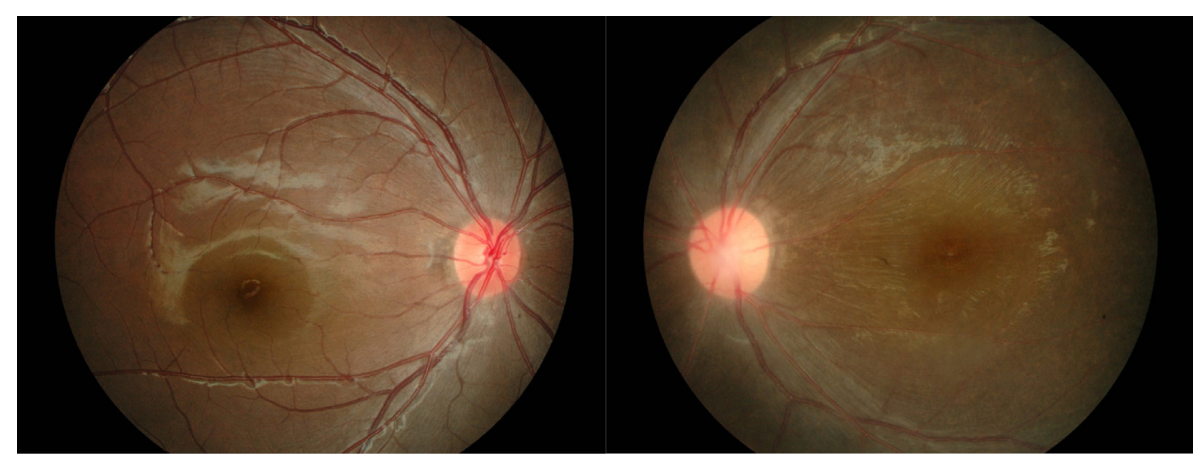

Figure I Left fundus (right photo) showed pigmentary changes of the retina with attenuated vessels and mild optic disk edema. Right fundus (left photo) was normal. 
Table I ERG findings in various studies of DUSN

\begin{tabular}{|c|c|c|}
\hline First author & Nematode & ERG on the affected eye \\
\hline \multirow[t]{3}{*}{ Carney ${ }^{10}$} & Migrating worm & Scotopic ERG had reduced a- and b-waves and \\
\hline & (800 $\mu \mathrm{m}$ in length) & an extinguished photopic ERG \\
\hline & Species not stated & \\
\hline \multirow[t]{2}{*}{ Kuchle $^{4}$} & Motile intraretina larva & Reduced scotopic and photopic amplitude \\
\hline & Bayliscariasis procyonis & \\
\hline \multirow[t]{5}{*}{ Audo"l } & Small nematode & Pattern ERG showed P50 reduction with reduced b:a ratio \\
\hline & (500 $\mu \mathrm{m}$ in length) & \\
\hline & Species not stated & Full field ERG showed inner retinal dysfunction with reduced rod ERG \\
\hline & & Reduction in all photopic ERGs \\
\hline & & Flash VEP was delayed \\
\hline \multirow[t]{3}{*}{ Anshu'12 } & Absence of worm & Multifocal ERG showed subnormal foveal respond with reduced \\
\hline & Appearance of sub RPE serpiginous tract & amplitude \\
\hline & Eosinophilia & \\
\hline \multirow[t]{3}{*}{ Current case report } & Absence of worm & Scotopic and photopic ERG had reduced a- and b-waves \\
\hline & Eosinophilia & \\
\hline & Toxocara IgG detected & \\
\hline
\end{tabular}

Abbreviations: DUSN, diffuse unilateral subacute neuroretinitis; ERG, electroretinogram; lgG, immunoglobulin G; RPE, retina pigment epithelium; VEP, visual evoked potential.

visualized ${ }^{13}$ but is not always possible. Photocoagulation will destroy the parasite and will subsequently reduce inflammation. However, when no worm is found despite repeated examinations, antihelminthic drugs are another choice of treatment. Antihelminthic drugs have been reported to be both effective and ineffective in the treatment of DUSN. ${ }^{14,15}$ Patients treated with antihelminthic drugs may require a longer treatment duration to reduce recurrence of the disease. ${ }^{14-16}$ Patients treated with antihelminthic drugs need to be monitored for the side effects of medication such as abdominal discomfort, jaundice, elevated liver enzymes, diarrhea, headache, and dizziness. In our patient, no worm was found and he was treated with antihelminthic medication for 5 days. His eye condition improved after treatment without any adverse effects. In view of the short duration of treatment, regular follow-up is recommended in our patient in case of recurrence.

Systemic steroids are used to control inflammation caused by the parasite and to help prevent deterioration of vision. ${ }^{17}$ Hypersensitivity reactions play a role in the visual prognosis of the DUSN patient. John et al studied guinea pig eyes and noted that there was a diffuse eosinophilic choroiditis, retinal pigment epithelial changes, and neuroretinal degeneration when Ascaris suum was injected intravitreally. ${ }^{18}$ Production of IgE antibodies and eosinophilia may cause degranulation of choroidal mast cells, antibody complement activation, and breakdown of the blood-retinal barrier. This may cause severe inflammation and further retinal damage. Thus, steroids may reduce inflammation, hasten recovery, reduce damage to the retina, and improve quality of life.

\section{Conclusion}

DUSN secondary to parasitic infection may cause slowly progressive vision loss or may even be asymptomatic to the patient. Ophthalmologists should be highly aware of DUSN when a patient presents with progressively reduced vision and posterior uveitis, particularly in children and young healthy adults. Early diagnosis of DUSN and effective treatment may help to prevent further visual impairment.

\section{Acknowledgment}

We would like to thank Universiti Sains Malaysia for providing the financial support for this case report (Research University Grant: 1001/PPSP/812064).

\section{Disclosure}

The authors report no conflicts of interest in this work.

\section{References}

1. Gass JDM, Gilbert WR, Guerry RK, Scelfo R. Diffuse unilateral subacute neuroretinitis. Ophthalmology. 1978;85:521-545.

2. Gass JDM, Braunstein RA. Further observations concerning the diffuse unilateral subacute neuroretinintis syndrome. Arch Ophthalmol. 1983; 101: 1689-1697.

3. Hedges TR. Diffuse unilateral subacute neuroretinopathy. In: Albert DM, Jakobiec FA, eds. Principles and Practice of Ophthalmology. Philadelphia, PA: Saunders; 2000;3:2167-2171.

4. Kuchle M, Knorr HLJ, Medenblik-Frysch S, Weber A, Bauer C, Naumann GOH. Diffuse unilateral subacute neuroretinitis syndrome in a German most likely caused by the raccoon roundworm, Baylisascaris procyonis. Graefe's Arch Clin Exp Ophthalmol. 1993;231: 48-51.

5. Gass JDM. Diffuse unilateral subacute neuroretinitis. In: Gass JDM Stereoscopic Atlas of Macular Diseases; Diagnosis and Treatment, 4th edition. St Louis, MO: CV Mosby. 1997:622-628. 
6. Barbazetto IA, Lesser RL, Tom D, Freund KB. Diffuse unilateral subacute neuroretinitis masquerading as white dot syndrome. $\mathrm{Br} J$ Ophthalmol. 2009;93:574-576.

7. Moraes LR, Cialdini AP, Avila MP, Elsner AE. Identifying live nematodes in diffuse unilateral subacute neuroretinitis by using the scanning laser ophthalmoscope. Arch Ophthalmol. 2002;120:135-138.

8. Magnaval JF, Malard L, Morassin B, Fabre R. Immunodiagnosis of ocular toxocariasis using Western blot for the detection of specific antiToxocara IgG and CAP for the measurement of specific anti-Toxocara IgE. J Helminthol. 2002;76(4):335-339.

9. Garcia CA, de Oliveira AG, de Lima CE, Rocha FN, Garcia Filho CA. Retinal nerve fiber layer analysis using GDx in 49 patients with chronic phase DUSN. Arq Bras Oftalmol. 2006;69:631-635.

10. Carney MD, Combs JL. Diffuse unilateral subacute neuroretinitis. Br J Ophthalmol. 1991;75:633-635.

11. Audo I, Webster AR, Bird AC, Holder GE. Progressive retinal dysfunction in diffuse unilateral subacute neuroretinitis. Br J Ophthalmol. 2006;90: 793-803.
12. Anshu A, Chee SP. Diffuse unilateral subacute neuroretinitis. Int Ophthalmol. 2008;28:127-129.

13. Stokkermans TJ. Diffuse unilateral subacute neuroretinitis. Optom Vis Sci. 1999;76:444-454.

14. Cortez R, Denny JP, Muci-Mendoza R, Ramirez G, Fuenmayor D, Jaffe GJ. Diffuse unilateral subacute neuroretinitis in Venezuela. Ophthalmology. 2005;112:2110-2114.

15. de Souza EC, Nakashima Y. Diffuse unilateral subacute neuroretinitis. Report of transvitreal surgical removal of a subretinal nematode. Ophthalmology. 1995;102:1183-1186.

16. Casella AM, Farah ME, Belfort R Jr. Antithelminthic drugs in diffuse unilateral subacute neuroretinitis. Am J Ophthal. 1998;125:109-111.

17. Myint K, Sahay R, Mon S, Saravanan VR, Narendran V, Dhillon B. Worm in the eye: the rationale for treatment of DUSN in south India. Br J Ophthalmol. 2006;90:1125-1127.

18. John J, Barsky HJ, Donnelly JJ, Rockey JH. Retinal pigment epitheliopathy and neuroretinal degeneration in ascarid infected eyes. Invest Ophthalmol Vis Sci. 1987;28:1583-1598.
Clinical Ophthalmology

\section{Publish your work in this journal}

Clinical Ophthalmology is an international, peer-reviewed journal covering all subspecialties within ophthalmology. Key topics include: Optometry; Visual science; Pharmacology and drug therapy in eye diseases; Basic Sciences; Primary and Secondary eye care; Patient Safety and Quality of Care Improvements. This journal is indexed on

Submit your manuscript here: http://www.dovepress.com/clinical-ophthalmology-journal

\section{Dovepress}

PubMed Central and CAS, and is the official journal of The Society of Clinical Ophthalmology (SCO). The manuscript management system is completely online and includes a very quick and fair peer-review system, which is all easy to use. Visit http://www.dovepress.com/ testimonials.php to read real quotes from published authors. 